\title{
The necessity of tailored control of irrupting pest populations driven by pulsed resources
}

\author{
Merlin C. Köhnke ${ }^{1,2}$ (D) Rachelle N. Binny ${ }^{3}$ - E. Penelope Holland ${ }^{4} \cdot$ Alex James $^{2,5}$
}

Received: 14 August 2019 / Accepted: 17 January 2020 / Published online: 13 March 2020

(C) The Author(s) 2020

\begin{abstract}
Resource pulses are widespread phenomena in diverse ecosystems. Irruptions of generalist consumers and corresponding generalist predators often follow such resource pulses. This can have severe implications on the ecosystem and also on the spread of diseases or on regional famines. Suitable management strategies are necessary to deal with these systems. In this study, we develop a general model to investigate optimal control for such a system and apply this to a case study from New Zealand. In particular, we consider the dynamics of beech masting (episodic synchronous seed production) leading to rodent outbreaks and subsequent stoat (Mustela erminea) irruptions. Here, stoat control happens via secondary poisoning. The results show that the main driver of the optimal control timing (June) is the population density of the control vector. Intermediate control levels are superior to higher levels if the generalist consumer is necessary as a control vector. Finally, we extend the model to a two-patch metapopulation model, which indicates that, as a consequence of the strong vector dependence, a strategy of alternating control patches yields better results than static control. This highlights that besides control level, also the design impacts the control success. The results presented in this study reveal important insights for proper pest management in the New Zealand case study. However, they also generally indicate the necessity of tailored control in such systems.
\end{abstract}

Keywords Pulsed resources · Mast seeding $\cdot$ Invasive species $\cdot$ Conservation biology $\cdot$ Pest management $\cdot$ Rodents $\cdot$ Stoat control

\section{Introduction}

Food webs affected by a pulsed resource are widespread and often include irrupting generalist consumer populations accompanied by generalist predator population outbreaks (Ostfeld and Keesing 2000; Polis et al. 2004). Heavy rainfalls or synchronous intermittent seed production events, commonly referred to as mast seeding are typical examples of pulsed resources (Allen et al. 2012; Kelly and

Merlin C. Köhnke

merlin.koehnke@uos.de

1 Institute of Mathematics, School of Mathematics/Computer Science, Osnabrück University, Osnabrück, Germany

2 Biomathematics Research Centre, University of Canterbury, Christchurch, New Zealand

3 Manaaki Whenua Landcare Research, Lincoln, New Zealand

4 Department of Biology, University of York, York, UK

5 Te Pūnaha Matatini, Wellington, New Zealand
Sork 2002; Herrera et al. 1998). Due to their short life span, rodent irruptions frequently form an integral part of such systems (Ostfeld and Keesing 2000). For example, in Japan, Castanopsis sieboldii masting is followed by high rat (Rattus rattus, Tokudaia tokunoshimensis, and Diplothrix legata) abundances. Rats, in turn, are preyed on by invasive mongooses (Herpestes javanicus) which are threatening endemic vertebrate species (Fukasawa et al. 2013). Singleton et al. (2010) describe bamboo masting (e.g., Melocanna) causing rodent irruptions in Asia. As rats damage rice crops, they can be cause for famines in those regions. Furthermore, heavy summer rainfalls in Argentina lead to irruptions of vegetation biomass followed by high corn mouse (Calomys musculinus) abundances associated with outbreaks of Argentine hemorrhagic fever virus epidemics (Ostfeld and Keesing 2000). Additional examples of epidemiological impacts of similar food webs are given by enhanced risk of the spread of rabies in Poland or increased Lyme disease risk in the United States (Jedrzejewska and Jedrzejewski 2013; Dalgleish and Swihart 2012). Due to extreme events accompanying 
climate change, these effects may become even more frequent in the future (Meerburg et al. 2009). Hence, understanding community dynamics affected by pulsed resources is not only crucial for ecosystem management but also epidemiological and even food security issues.

In New Zealand, mast seeding beech (Nothofagus) trees form part of about half of local indigenous forests (Wardle et al. 1984; Wiser et al. 2011). Of the 32 terrestrial mammal species in New Zealand, 29 are reducible to biological introductions, and many pose serious risks to indigenous avifauna (King 2005; Ruscoe et al. 2006). Hence, it is a country in which management of such ecosystems is particularly urgent. Of New Zealand's endemic birds, $41 \%$ are already extinct while $77 \%$ are threatened and suffering from irruptions of invasive mammals such as possums (Trichosurus vulpecula), stoats (Mustela erminea), and rats (e.g., Rattus rattus) (Innes et al. 2010). Already Riney (1959) suspected a strong connection of mast seeding and threats to native birds. In particular, masting leads to increases of mice, and rats followed by stoat irruptions and high predation pressure on birds-a relationship which is now widely confirmed, e.g., by linking mohua (Mohoua ochrocephala) breeding success to stoat irruptions after years with high seed fall (King 1983; O’Donnell et al. 1996).

Due to the significant threat to indigenous birds, including the national animal of New Zealand, the kiwi (Apteryx), the New Zealand Department of Conservation developed a control program named "Battle for our Birds" (Elliot 2016). This program mainly consists of pest control using aerial application of biodegradable sodium fluoroacetate (1080) after beech masts (Elliot 2016). If prefeed is applied, the toxins poison the rats while the toxic rats kill stoats via secondary poisoning (Murphy et al. 1999). In 2014, the operation covered 694,000 ha corresponding to $10 \%$ of New Zealand's indigenous forest area, which was highly effective in reducing rat and stoat tracking rates (Elliot 2016). However, costs of such operations and public concerns regarding environmental side-effects limit the application of 1080 (Green and Rohan 2012). Hence, it is essential to understand the dynamics to optimize the handling of existing resources and to avert environmental risks.

In this study, we develop a mathematical model describing a food web consisting of a pulsed resource, a generalist consumer, and a generalist predator with discrete breeding times and parameterize it as an example with regard to the seed-rat-stoat dynamics from New Zealand. We use the model to improve pest management by optimizing control design, control timing, and control intensity. Control design refers to the control patch size and the control frequency in each of these patches. The results emphasize the necessity of tailored control in such systems.

\section{Model}

In the case study, beech (Nothofagus) seeds $F$ are the primary resource (see Fig. 1), and seed fall and seed decay are the main drivers of their dynamics. Seed fall happens irregularly via beech masting on average every 4-6 years predominantly in autumn (February-May) (Wardle et al. 1984; Ruscoe et al. 2005). High resource abundances after mast events lead to outbreaks of ship rats (Rattus rattus) which prey on seeds (link 1), and also on other seed predators (McQueen and Lawrence 2008; King et al. 2011; Bridgman et al. 2013). Typically, ship rats breed in spring and summer (September-February), but when resources are highly abundant, as in years with high seed fall, breeding over winter occurs as well (King et al. 2011). Populations of other seed predators with short life spans, e.g., mice, irrupt similarly (link 2). Stoats (Mustela erminea), which feed on the seed predators, act as a generalist predator in this system. However, seasonal breeding of stoats is

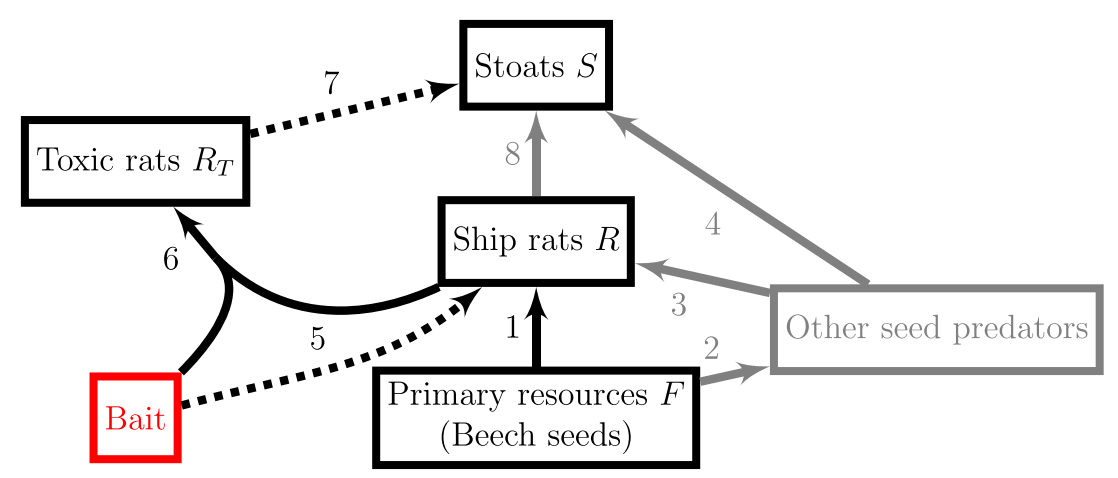

Fig. 1 We consider a food chain with three trophic levels in which top predator control is only possible via the consumer. The figure shows a conceptual model of the system. Solid lines indicate a positive influence, while dashed lines indicate a negative influence. The red rectangle shows the control mechanism. The gray part of the diagram is modeled implicitly. We use the numbers beside the edges for references in the text 
temporally more restrictive, only taking place in early spring (September-October) (O'Connor et al. 2006). The number of offspring produced strongly depends on their habitats' resource abundance ranging from no breeding at all up to 18 kits (King et al. 2003). Hence, a delayed high stoat abundance follows high seed consumer abundance driven by beech masting (O'Donnell et al. 1996). Due to the impact on the native fauna, control focuses on both stoat and ship rat populations. Sodium fluoroacetate (1080) baits are used to control rats and stoats (Elliot 2016). Here, stoat control happens via secondary poisoning (Murphy et al. 1999). Hence, rats eat baits (link 5) and are converted into toxic rats (link 6). Stoats then get poisoned by feeding on toxic rats (link 7). Note that we include a predation effect of stoats on non-toxic rats in the model only implicitly as rats usually only form a minor part of the stoats' diet. In particular, without poisoning, only $<10 \%$ of the gut content of stoats contained rats (King and Moody 1982; King 2005). After 1080 poisoning, this is no longer true, presumably because stoats also feed on the carcasses (Murphy et al. 1999). By modeling it implicitly, we mean that we parameterized a term representing predation on all seed predators (including rats) using observations. Including a weak predation term as a direct link would have been equally possible. However, the other seed predators would still be necessary for agreement with observations. Hence, the model would have been more complicated and also harder to parameterize.

In this section, we introduce the model by successively aggregating the corresponding submodels. We refer to this model as local as it does not include dispersal. In the "Metapopulation model" section, we develop a metapopulation model to account for such spatial processes.

Table 1 lists the parameters used in this study with corresponding references. If available, we have used literature values. Otherwise, we calibrated the particular submodels using parameter estimations based on qualitative and quantitative results of previous studies.

\section{Pulsed resource}

We use the delta temperature $(\Delta T)$ model introduced by Kelly et al. (2013) to describe resource fluctuations. Previous theoretical studies have already exploited this model (Holland and James 2015; Holland et al. 2018), and applications to different plant species revealed a good correlation between prediction and data (Kelly et al. 2013; Pearse et al. 2014). We use mean annual summer temperatures over the previous two years $\Delta T_{y}=T_{y-1}-$ $T_{y-2}$ to model resource abundance in year $y$. For the application of the model, we generated a 500-year random sample temperature time series. As in Holland et al. (2018),

$T_{y} \sim \mathcal{N}(14,1)$ represents mean summer temperatures between 1972 and 2014 in the Orongorongo Valley in New Zealand. We predict seed fall based on these data and the log-linear model

$\log _{10} F_{y}=0.33+0.97 \Delta T_{y}+\epsilon_{y}$

parameterized using data from the Orongorongo Valley by Holland and James (2015) with $\epsilon_{y} \sim \mathcal{N}(0,1.3)$ to match the correlation between seed fall and temperature as reported by Kelly et al. (2013).

The differential equation

$\frac{\mathrm{d} F}{\mathrm{~d} t}=\sigma(t)-h F-f(F) R$

models the annual rate of change of food abundance $F$ (seeds $\mathrm{m}^{-2}$ ). Here, $h$ is the annual degradation rate of seeds, and $\sigma(t)$ describes the resource delivery, i.e., in this case, beech seeding given by

$\sigma(t)= \begin{cases}\frac{F_{y}}{0.25} & \text { if } 0 \leq t-\lfloor t\rfloor<0.25 \\ 0 & \text { otherwise. }\end{cases}$

$\lfloor t\rfloor$ denotes the floor function giving the largest integer smaller than $t$. Hence, seeding takes place in the form of a steady influx to the food abundance in the first quarter of the year. The start of the year is defined to be in February as this is the time in which masting typically starts. The term $f(F) R$ represents the consumption of the generalist consumer $R$ with functional response $f(F)$, which we describe in the following section. Figure 2 row 5 shows a 10 -year sample time series with 2 years with high seed fall to as an illustration of the seed dynamics.

\section{Generalist consumer}

As rodents are prominent examples of generalist consumers (Ostfeld and Keesing 2000), it is reasonable to model ship rats (Rattus rattus) as a representative example of a generalist consumer. The differential equation

$$
\begin{aligned}
\frac{\mathrm{d} R}{\mathrm{~d} t}= & \Phi_{R}(F, R)=R\left(\rho-\mu_{R} R+\alpha_{1} f(F)\right. \\
& \left.+\alpha_{2} f\left(F_{R 0}\right)-B(t)\right), \\
F_{R 0}= & \frac{\int_{t-1}^{t} F\left(t^{\prime}\right) \mathrm{d} t^{\prime}}{1+\beta \int_{t-1}^{t} B\left(t^{\prime}\right) \mathrm{d} t^{\prime}} .
\end{aligned}
$$

models the temporal population dynamics of the ship rat. As ship rats' breeding success declines with density, we consider both density-independent $\rho$ and density-dependent $\mu_{R}$ birth/death processes (Efford et al. 2006). Ship rats are seed predators (link 1 in Fig. 1) (King et al. 2011). As there is evidence for predator satiation during years with high 
Fig. 2 Phenomenological dynamics follow what is known from data. A part of a sample run of the local model is shown. Beech masting takes place in year 2 and year 8 of the time series. Bait is applied only in the second mast event (year 8)
1)

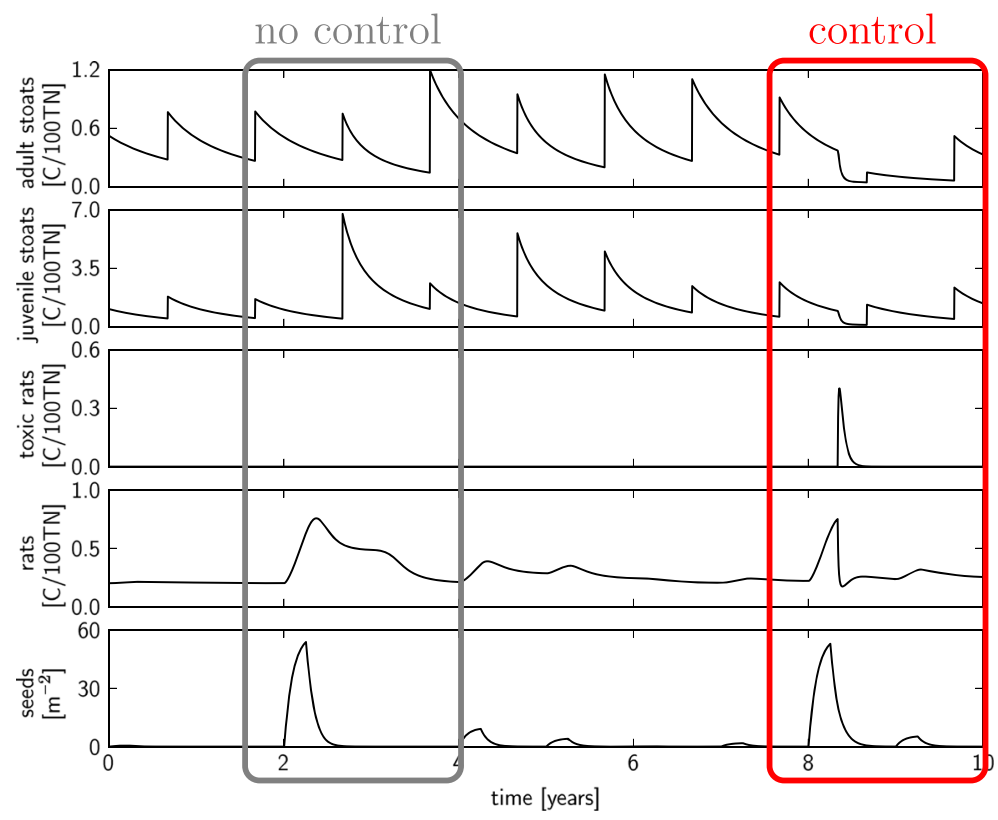

seed fall (Kelly and Sork 2002), we assume the functional response

$$
f(F)=c \cdot\left(1-e^{-\epsilon F}\right)
$$

to be of Ivlev type. Note that one can equally justify another saturating functional response such as Holling type II. Some models show structural sensitivity against this choice (see e.g., Fussmann and Blasius (2005) and Cordoleani et al. (2011)). However, the results presented in this study do not change qualitatively using Holling type II (results not shown).

A pure predator-prey relationship between rats and seeds would lead to a delayed peak in rat abundance, which would decrease again when seeds degrade. Conversely, data show that rat abundance is high between 15 and 20 months after a year with high seed fall (Elliott and Kemp 2016; Kemp et al. 2018). This is because the diet of ship rats also depends implicitly on beech seeds (links 2 and 3 in Fig. 1). For instance, they also prey on mice, particularly after beech years with high seed fall (McQueen and Lawrence 2008; Bridgman et al. 2013). This is taken into account by the term $F_{R 0}$ assuming that ship rats also benefit implicitly from seed fall of the last 12 months due to secondary food sources. As an alternative, we could have modeled these secondary as another state variable. However, this state variable would have incorporated a whole set of species that depend (partially) on seeds and are eaten by rats. Thus, parameterization would have been rather difficult. Furthermore, the model would have become even more complicated. Hence, we decided to model it in this indirect way to achieve the observed qualitative behavior. The resulting rat dynamics following a year with high seed fall are evident in Fig. 2 row 4 in the second year of the time series. Rat abundance is particularly high when seed abundance is high as well but stays high for about 15 months before it falls back to the pre-mast level. This is in agreement with what is known from data (Elliott and Kemp 2016; Kemp et al. 2018).

The denominator of $F_{R 0}$ describes the impact of bait application $B(t)$ on secondary food sources, e.g., mice. If no bait is applied, the denominator is 1 . Conversely, if bait application took place in the last 12 months, secondary food sources are affected. Here, the parameter $\beta$ represents bait efficacy regarding secondary resources. Bait application can be subject to different control strategies, e.g., annual control or control in years with high seed fall. Then, baits are applied at times $t_{i}^{* b}$, where $i$ denotes the $i$ th bait application. Following Holland et al. (2018),

$B(t)= \begin{cases}B_{0} \exp \left(-d\left(t-t_{i}^{*}\right)\right), & \text { if } t_{i}^{* b} \leq t<t_{i+1}^{* b} \\ 0, & \text { otherwise }\end{cases}$

models the dynamics. Hence, bait application happens with an impulse with intensity $B_{0}$. Note that the value of $B_{0}$ has no actual ecological meaning. However, to compare it with data, it can be converted into killing proportions (see Appendix 2). After application, bait decays exponentially with decay rate $d$. Note that bait is not carried over to the next year. This is a reasonable assumption as, after one year, bait has already decayed to a fraction of $2 \cdot 10^{-22}$ of its original value. Rats are also directly affected by bait applications (link 5 in Fig. 1) which turn rats $R$ into toxic rats $R_{T}$ (link 6 in Fig. 1). The differential equation

$\frac{\mathrm{d} R_{T}}{\mathrm{~d} t}=R B(t)-\left(d_{i}+\iota S\right) R_{T}$ 
describes the temporal dynamics of the toxic rat population. The term $R B(t)$ is the conversion term converting susceptible ship rats into toxic rats depending on encounters between rats and bait, which is assumed to be proportional to the product of the densities. The second term describes rat mortality due to poison and subsequent natural degradation of toxin in the carcasses as well as feeding of the generalist predator on toxic rats. Year 8 in the time series of Fig. 2 visualizes the effect of bait application on the rat population. The bait application converts a large proportion of rats into toxic rats, which decay quickly. Conversely to the first year with high seed fall in the time series (year 2), rats are at average (non-mast year) densities following the control application.

\section{Generalist predator}

We consider stoats (Mustela erminea) as generalist predators and distinguish between juvenile $S_{y}$ (subscript for young) and adult stoats $S_{o}$ (subscript for old). The only difference between age classes we take into account is the density-independent mortality as young stoats have significantly higher mortality rates (King et al. 1996). The set of equations

$$
\begin{aligned}
\frac{\mathrm{d} S_{y}}{\mathrm{~d} t}= & \Phi_{S_{y}}\left(F, R_{T}, S_{y}, S_{o}\right)=S_{y}\left(-\mu_{S_{y}}-\mu_{S 2}\left(S_{y}+S_{o}\right)-\kappa R_{T}\right) \\
& +\left(\left(S_{y}+S_{o}\right) g\left(F_{S 0}\right)-S_{y}\right) \sum_{i=0}^{\infty} \delta\left(t-t_{i}^{* r}\right) \\
\frac{\mathrm{d} S_{o}}{\mathrm{~d} t}= & \Phi_{S_{o}}\left(F, R_{T}, S_{y}, S_{o}\right)=S_{o}\left(-\mu_{S_{o}}-\mu_{S 2}\left(S_{y}+S_{o}\right)-\kappa R_{T}\right) \\
& +S_{y} \sum_{i=0}^{\infty} \delta\left(t-t_{i}^{* r}\right) \\
F_{S 0}= & C+\gamma \int_{t-1}^{t} F\left(t^{\prime}\right) \mathrm{d} t^{\prime}
\end{aligned}
$$

describes the dynamics of the stoat. Stoat populations show density-dependent mortality due to competition (O'Connor et al. 2006). Hence, the two first terms are similar to the rat dynamics and describe density-independent and densitydependent death processes, respectively. The third term $\kappa R_{T} S$ depicts stoat mortality due to secondary poisoning by toxic rats (link 7 in Fig. 1). The last term represents the rather complicated breeding biology of stoats (see, e.g., King and Moody 1982). Depending on the resource richness of the environment, stoats may not breed at all or give birth to up to 18 kits (link 4 in Fig. 1) (King et al. 2003). This is taken into account by the term $F_{S 0}$ with saturating functional response (Ivlev type) (Jones et al. 2011).

$$
g(F)=c_{s} \cdot\left(1-e^{-\epsilon_{s} F}\right)
$$

However, as not all of the stoats' diet depends on seed fallrelated organisms, the constant $C$ leads to a small number of offspring also in non-mast years. The sum of delta functions represents discrete annual breeding events with time $t_{i}^{* r}$ representing the $i$ th reproduction event as kits are born mainly between September and October (O'Connor et al. 2006). Note that juvenile and adult stoats give birth. Female stoats become sexually mature when they are still in the nest (3-5 weeks old) while males' sexual maturity starts in August of the next year (Mcdonald and Harris 2002; Norbury 2000). Furthermore, note that breeding success is assumed to be independent of bait application, although stoats also prey on mice. This is due to the high flexibility of their diet also including various seed predators which are not affected by the bait application, e.g., passerine and weta (Anostostomatidae and Rhaphidophoridae) (Murphy et al. 2016; Smith et al. 2005; Wyman et al. 2011).

In the case of no control, the year with high seed fall is followed by a high density of juvenile stoats due to the high amount of offspring. These turn into adult stoats in the following year. Conversely, in the case of the controlled year with high seed fall, the toxic rats yield a high rate of secondary poisoning for both juvenile and adult stoats. Thus, lower stoat densities at the reproduction event yield a smaller number of offspring.

\section{Metapopulation model}

Due to the costs of aerial 1080 application and due to public concerns, bait application only takes place locally, i.e., aerial bait application all over the country is not feasible. To investigate the impact of reinvasion of adjacent habitats, we develop a metapopulation model. In particular, we consider two connected patches with separate dynamics. The seed fall dynamics and the dynamics of toxic rats are equal in both patches. Susceptible rats $R$ can migrate between patches 1 and 2 with a dispersal rate $D_{R}$ yielding

$\frac{\mathrm{d} R_{1}}{\mathrm{~d} t}=\Phi_{R}\left(F_{1}, R_{1}\right)-D_{R}\left(R_{1}-R_{2}\right)$.

The dispersal rate is independent of the habitat as simple diffusive behavior is a good approximation for the short time behavior of other rodents (Abramson et al. 2006). This is consistent with the approximately uniform distribution found for ship rats (Innes 1990). Furthermore, ship rats only show low territorial behavior (Dowding and Murphy 1994). Note that the equation for patch 2 is similar to replacing subscripts 1 with 2 and vice-versa.

One crucial difference between stoats and rats is that dispersal rates differ significantly between juvenile and adult stoats mainly due to the strong competitive exclusion (Erlinge 1977). In particular, immigration predominantly happens via young stoats (King and McMillan 1982). This 
is consistent with the observation of a dispersal season between November and May following the birth of juvenile stoats (Elliott et al. 2010). To take this complexity into account, the dispersal processes between patches 1 and 2 in the model differ between juvenile and adult stoats

$$
\begin{aligned}
\frac{\mathrm{d} S_{y_{1}}}{\mathrm{~d} t} & =\Phi_{S_{y}}\left(F_{1}, R_{T_{1}}, S_{y_{1}}, S_{o_{1}}\right)-p\left(S_{O_{1}}\right) S_{y_{1}}+p\left(S_{o_{2}}\right) S_{y_{2}}, \\
\frac{\mathrm{d} S_{o_{1}}}{\mathrm{~d} t} & =\Phi_{S_{o}}\left(F_{1}, R_{T_{1}}, S_{y_{1}}, S_{o_{1}}\right)-D_{S_{o}}\left(S_{o_{1}}-S_{o_{2}}\right) .
\end{aligned}
$$

As adult stoats have already settled in a territory with a certain home range, we assume a constant dispersal rate for simplicity. Conversely, juvenile stoats disperse in order to find a suitable territory. Hence, their dispersal depends on the density of settled (adult) stoats in the patch

$p\left(S_{o}\right)=\frac{D_{S_{y}}}{1+e^{-\psi S_{o}}}$.

The choice of this function is arbitrary to a certain extent. However, it is a simple approximation of the primary driver of stoat dispersal. It is sigmoidal, depending on adult stoat density. Note that numerical simulations revealed that results obtained in this study are robust against the exact choice of this function. With high local adult stoat abundance, the likelihood of finding a spare territory in this patch is low, and thus the dispersal rate of young stoats increases. The equations describing the dynamics of patch 2 are similar, replacing subscripts 1 with 2 and vice-versa.

Figure 3 shows a part of a sample run of the system including seed, rat, stoat, and bait dynamics for the metapopulation model. Dispersal of rats is negligibly small in this case, while the reinvasion of stoats has a definite effect on the dynamics.

\section{Plague metric}

This study aims to find patterns for efficient, tailored predator control. This is necessary if the predator is a pest, e.g., due to crop damage, its role as a disease vector, or a threat for other species. It is essential to define the plague metrics corresponding to the problem to obtain consistent results. For instance, the endangered bird kaka (Nestor meridionalis) is particularly vulnerable to nest predation in its breeding season, which is taking place mainly before beech masts (Wilson et al. 1998; Moorhouse et al. 2003). Hence, only specific years matter. Conversely, some problems do not only depend on the predator but also depend on the consumer, e.g., Mohoua ochrocephala is preyed on by both rats and stoats (Innes et al. 2010). In this study, we consider the impact of stoats on kiwi (Apteryx) populations as an example. As a metric, we have chosen mean stoat densities between November and March as kiwi chicks are particularly vulnerable to stoat predation in this time (Robertson et al. 2016). We define control success as the inverse of the mean stoat density between March and November.

\section{Results}

\section{Local dynamics}

We have compared three different control strategies in the local case, i.e., annual bait application, quadrennial (every fourth year) bait application, and bait application only in years with high seed fall. Here, we define such a year as a
Fig. 3 Reinvasion from adjacent patches can significantly alter control success. The figure shows a part of a sample run of the local model. The dispersal rate of the rats is $D_{R}=10^{-2}$. Note that this is too small to lead to a visible effect on such a time scale for rat dispersal while the significantly higher stoat dispersal already is having a noticeable impact given by the difference between the gray and the black line (see the

"Metapopulation dynamics" section for more details on this)
1)

2)

3)

4)

(a) patch with control without reinvasion with reinvasion
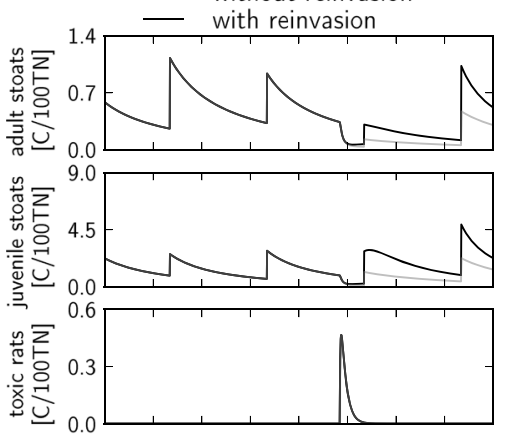

5)
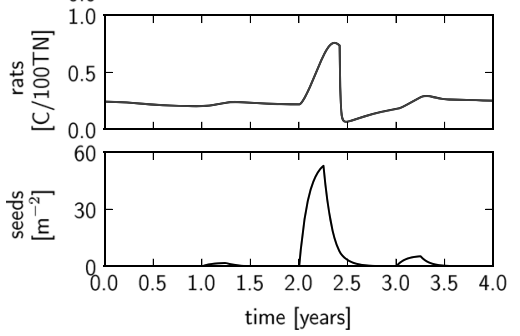

(b) patch without control

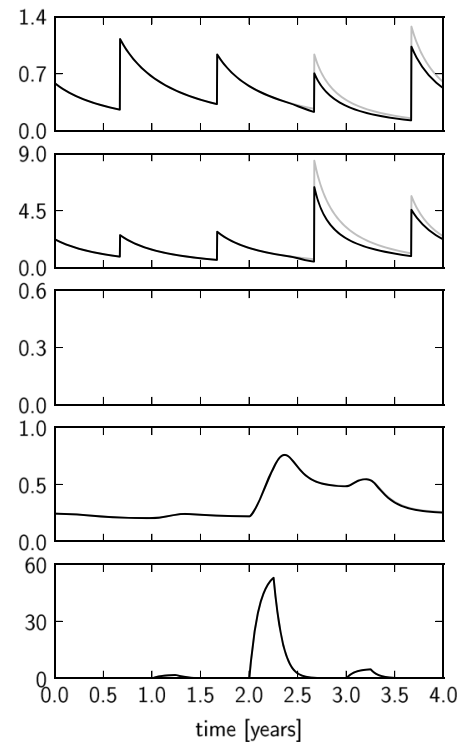


year in which seed fall is in the first quartile of the highest annual seed fall. Hence, this also happens once in four year on average.

The optimal control timing is between June and July (see Fig. 4). This corresponds to the time of the maximum density of the rats. This is because a higher rat density leads to higher toxic rat densities and thus to higher poison probabilities.

The optimal control level is at about $B_{0}=100$. So far, the control level has no practical meaning. However, one can convert it into a killing proportion of about $95 \%$ (see Appendix 2). Given this optimal control level, the impact of the control timing is small. Conversely, the impact of control intensity at a fixed time of the year is high. In particular, high levels of control, i.e., $B_{0}>200$, yield the same results as in case of no control. This upper limit beyond which higher control levels are detrimental exists because the rat population may locally go extinct, and there is no other efficient way to control the stoat population. However, the value of the upper limit depends on the control setting. For instance, a lower control frequency gives the rat population more time for recovery. One exception is control application at the end of the year, i.e., January by the definition used in this study. Given a high control intensity, a minimum stoat density is apparent for this timing. However, this is an artifact resulting from the discrete start of seed fall at the beginning of the year. Bait application directly before this time has a minor influence as the rat population is very low and will immediately recover due to the high resource abundance.

Applying control every fourth year corresponds to a less efficient control strategy. Higher control levels are necessary for optimal control success. However, very high control intensities do not impair control success as in the case of annual control. Furthermore, an optimal control timing in June is visible. Note that the asymmetry in the temporal dependence for bait application in years with high seed fall is due to the seed fall at the beginning of the year. Applying high levels of control at this time, the rats cannot recover the rest of the year as the food has already degraded. This can lead to extinction of the rats and, therefore, to extinction of the control vector of the stoats. However, note that the extent of the asymmetry is an artifact resulting from the discrete seed fall start.

Figure $4 \mathrm{c}$ shows the dependence of the control success on the timing and the control intensity if control takes place only in years with high seed fall. In general, the control yields higher stoat densities with these control strategies compared with the case of annual control. However, it is more effective than applying control quadrennially, although the number of control application is identical in the long term. The optimal timing for control is in June. This is the same as in the case of annual and quadrennial control applications. However, the control timing has a
Fig. 4 Control application only in years with high seed fall needs more effective control and strongly depends on the timing. The figure shows the dependence of the control success on the timing and the intensity of the control for three different control strategies. The mean stoat density in the relevant time of the year represents control success (see the "Plague metric" section). The white lines denote the breeding time of stoats

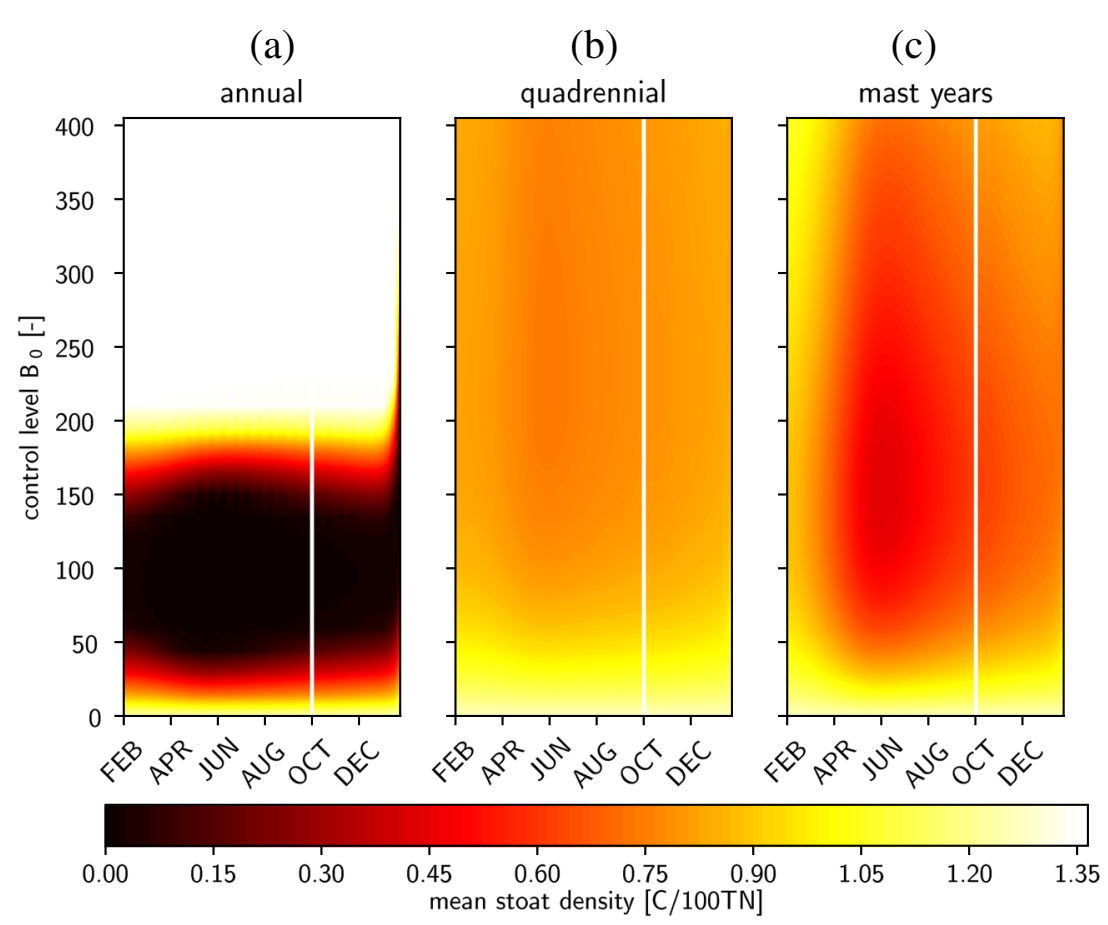


higher and more complex impact in this case. While the effect of control slightly earlier or slightly later than the optimal timing is the same in the case of annual and quadrennial control, it is asymmetric in the case of control in years with high seed fall. Furthermore, higher control levels are possible and also necessary to obtain optimal control success.

\section{Metapopulation dynamics}

The results of the metapopulation model are restricted to the case of control in years with high seed fall as this is the more feasible strategy due to the lower costs and less social concerns (Green and Rohan 2012). Note that the dispersal rates of young and old stoats are defined in terms of the rat dispersal rate (see Table 1 in Appendix 1). Hence, the relation between the dispersal abilities does not change, but the absolute values do. Changing the absolute values may correspond to different species. However, note that here, it corresponds to varying patch size as dispersal only happens between the two patches. The optimal control timing is June, as in the local results (not shown here). Figure 5 visualizes the effect of the dispersal rate and the control intensity, assuming that the bait application takes place in June.

For plot (a), control has always been applied in the same patch, while the control patch switched with every bait application for plot (b). In both control strategies, one achieves the optimal control outcome with high dispersal abilities because reinvasion increases the potential control vector density. However, in the case of alternating control patches, the corresponding optimal control level is higher than in the case of a constant control patch. Furthermore, the maximum effect of the control is higher in the case of alternating control patches, even if the same level of control is applied.

A clear suboptimal dispersal rate at $D_{R} \approx 10^{-2}$ year $^{-1}$ exists. In that case, the mean stoat density, i.e., the inverse of the control success, has a maximum independent of the control level. De- or increasing the dispersal rate sufficiently yields significantly higher control success. In both cases, the effect of a change in the dispersal rate is the highest close to the suboptimal point and gets lower further away. Furthermore, the figure depicts the influence of the control level. At low and intermediate control levels, i.e., $B_{0} \leq 100$, a change in control level has a high impact. Increasing the control level, the rate of change of the control efficacy with varying control levels tends to zero or is even reversed in the case of a constant control patch.

The suboptimal value for the dispersal rate for which the control is least effective results from a trade-off of the dispersal influence. At low dispersal rates, both rat and stoat dispersal is low. Lower stoat densities in the patch produce less offspring. Furthermore, after the breeding event, stoats reinvade at a lower rate, which means that
Fig. 5 Alternating the control patch yields higher control success while a suboptimal patch size exists independent of the control strategy. The figure shows the influence of the rat dispersal rate and control level on the mean stoat density $\left(S_{y}+S_{o}\right)$ in Apteryx chick vulnerability time. In plot (a), control is applied in the same patch each bait application. Conversely, control application takes place in an alternating manner in plot (b), i.e., the control patch switches after each application. Note that the abscissa is log-scaled (a)

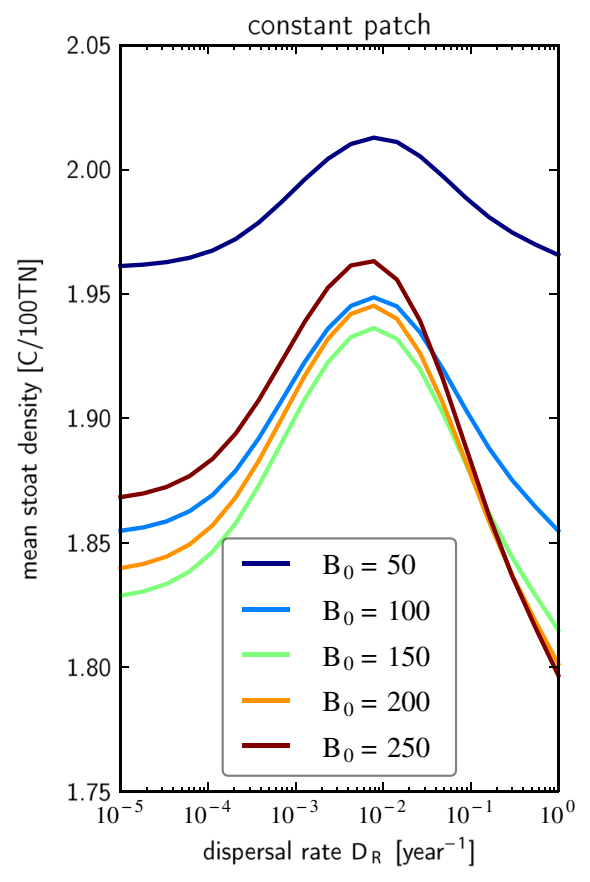

(b)

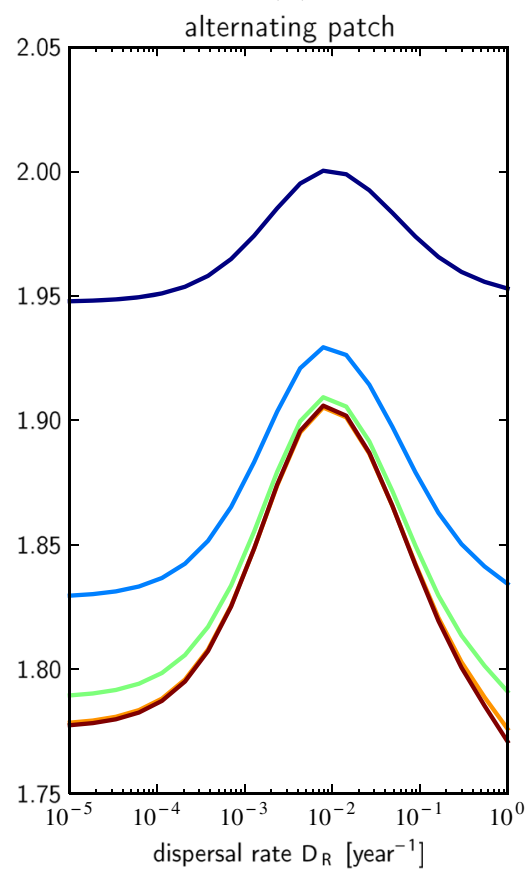


the stoat population stays low for a longer time while the stoat population in the other patch suffers from higher density-dependent mortality. Conversely, at high dispersal rates, stoat reinvasion is very fast. However, in this regime, invasion rates of rats are important as well. Due to the fast reinvasion, a higher number of potential vectors to control the stoat population is abundant. Furthermore, the extremely high stoat reinvasion rate leads to a higher density in the control patch already shortly after control application. This, in turn, leads to a larger number of stoats, which one can potentially control via secondary poisoning. However, both effects are saturating for very high or low dispersal rates respectively because very low dispersal rates tend to zero, and higher dispersal rates have no impact anymore if densities are already equal in both patches. At intermediate dispersal rates, the dispersal rate of rats is too low for increasing the vector density efficiently directly after bait application while stoat dispersal rates are already high enough to decrease the impact of density-dependent death processes in the uncontrolled patch. However, in the long run, reinvasion still has an effect decreasing natural densitydependent mortality in the patch, which is not controlled and leading to higher stoat densities in the controlled patch (see Fig. 3 for a sample time series showing this relationship).

\section{Discussion}

\section{Control timing}

Independent of the control strategy or the setting, i.e., local or metapopulation dynamics, the optimal control timing is in June. This also holds for other species which are mainly preyed on by stoats. An example is given by the kaka, which we have also modeled using the same approach (not shown here). Previous studies about rodents have suggested mid-September as optimal control timing (Elliot 2016; Holland et al. 2018). This demonstrates the importance of tailored control, i.e., control depending on the target. If the rodents act as a control vector, the most effective control corresponds to the highest vector densities. In midSeptember, the rat population has already decreased due to intraspecific competition which is why mid-September would be too late for optimal control. Conversely, if rodents are not only control vectors but also control targets themselves, this does no longer hold. However, note that especially in the case of annual bait application but to a certain extent also for bait application in years with high seed fall, controlling in mid-September would still reduce the mean stoat density significantly (although not optimally) if the control level is high enough. In this case, the high control level partly compensates for the lower rat densities because a higher proportion of rats turns into toxic rats. However, applying the control too early is also ineffective as the rat population mainly grows in the first quarter of the year when masting takes place.

Due to public concerns, the annual control application is not feasible. If we neglected public concerns, applying bait annually at a lower level might still yield better results than applying baits in mast years at higher control levels. However, the reduced control level reduces bait material but not (significantly) the costs of the aerial operations. Hence, the results presented here underline the importance of the right timing in years with high seed fall. This calls for better mast identification (e.g., model predictions as in Kelly et al. 2013) and faster decision-making processes. This becomes even important as the effect of timing is higher if one applies control in years with high seed fall. This is due to the higher control level, which is necessary in this case, which increases the influence of bait application time. However, in practice, data on seed abundance determining years with high seed fall are often usable not earlier than July, and afterward, a political decision-making process is still necessary (Elliot 2016).

\section{Control intensity}

The results presented in this study reveal one major problem of secondary poisoning, which is the dependence on the vector. Independent of the control strategy, an upper limit of the control intensity exists beyond which higher control levels are detrimental due to the dependence on the control vector. Note that we did not include the effect of 1080 on mice as a secondary (seed predator) food source, which may weaken this effect as the control does not solely depend on the rats. The qualitative results do not depend on this, and even the quantitative results are robust against this distinction if mice were similarly prone to the bait as rats. However, note that 1080 is not as effective for controlling mice.

This critical control density becomes higher with lower control frequency and higher reinvasion of rats through adjacent patches. However, especially if control patches are large and reinvasion is limited, it is essential to note that a high control intensity can be less efficient management in the long run. Before reaching this critical level, the effect of an increase in the control intensity saturates. From a management perspective, this is positive because it means that we can apply significantly lower control levels without losing much of the control success. But this can act as a 
buffer reducing the risk of killing the vector. The optimal control intensity we found was $B_{0} \approx 150$ in the case of control in years with high seed fall without reinvasion and $B_{0} \approx 250$ in the case of alternating patch control. However, $B_{0} \approx 150$ is nearly as effective as the optimal intensity in the alternating patch control case. This is consistent with data. A reduction in the bait sowing rate, from $11 \mathrm{~kg} / \mathrm{ha}$ to 4 $\mathrm{kg} / \mathrm{ha}$ for possum control, for instance, did not significantly alter the killing proportion (Warburton and Cullen 1995).

This optimal value corresponds to a killing proportion of about $95 \%$. The current management goal of the Department of Conservation in New Zealand is to reduce rat tracking rates to 5\% in years with high seed fall via 1080 application (Elliot 2016). As rat tracking rates in years with high beech seed fall can approximately be between $80 \%$ and 100\% (Elliot 2016; Kemp et al. 2018), the goal is in good agreement with the optimal intensity.

\section{Control strategy}

For the local dynamics, the results clearly show that annual control is much more effective than applying control only in years with high seed fall. However, depending on the specific case, this may not be feasible due to different environmental trade-offs, economic restrictions, and public concerns. Considering dispersal from adjacent patches using the metapopulation model indicates that the strategy of alternating control patches yields better results than static control. This may be counter-intuitive at first glance as focusing on one patch may provide a refuge area for endangered species, which might make sense in some cases. However, considering the mean of the pest population (stoats) over the two patches, the alternating strategy has two advantages. First, the pest population in a patch has more time to recover, and higher pest densities yield higher poisoning probabilities and hence a higher efficacy in that patch. And second, the vector population (rats) has a longer time to recover between bait applications. Hence, a higher potential vector density exists in the patch. This is also the reason why the optimal control level is higher in the case of the alternating strategy. For a given control level, the alternating patch strategy yields better results. However, the optimal control strategy, in this case, clearly also depends on the conservation objective. For some endangered species, refuge areas may be still better suited. This probably depends on the dispersal abilities of this species. Species with high dispersal abilities, e.g., birds capable of flying, may make less use of the refuge areas than species with small home ranges. Further research relating pest management to conservation outcomes for a range of threatened species, and the effects of dispersal on these outcomes, is needed.

\section{Conclusions}

In this study, we have developed a model describing the dynamics of a food chain consisting of a generalist consumer (e.g., ship rats) and a generalist predator (e.g., stoats) affected by a pulsed resource. We have applied it to a case in New Zealand to show how such a model can support pest management strategies. In particular, it indicates the importance of the control vector for a proper management strategy.

The maximum in the population density of the control vector determines the optimal timing, which is June for rats. This implies that given that various predators (e.g., stoats and possums) feed on the same vector, the optimal control timing stays constant. High control intensities can be counterproductive if they yield extinction of this vector. Hence, intermediate control levels are more effective in the long run. This can lead to huge cost savings. For instance, the reduction of 1080 bait usage for possum control has saved 8.9 million dollars per year without reducing the control success (Morgan et al. 1997). However, one can influence this dependence by the control strategy, e.g., alternating control patches allow for longer recovery periods of the control vector species. This also depends on the patch size. Especially intermediate patch sizes in which reinvasion of the generalist predator may be fast while reinvasion of the generalist consumer is still negligibly small can have a negative impact on the control success. From a management perspective, this intermediate dispersal regime can be prevented by either applying very large or very small control patches or by changing dispersal abilities in another way, e.g., by separation of patches using (leaky) fences. The patch sizes (represented by the proxy of the rats' dispersal rate) yielding high control success found in this study depend not only on the bait application but also on indirect effects after the reinvasion, such as higher densitydependent mortality in the case of low stoat reinvasion rates. Hence, considering spatial dependencies like this makes the combinations of different control mechanisms such as chemical (bait) and biological (density-dependent) mechanisms necessary. Furthermore, this indicates that the spatial design of bait application may play an important role in the pest management.

Note that only the stoat density gives the control success metrics underlying the results of this study. This means that low mean stoat densities in a critical time interval 
correspond to high control success independent of the ship rat population. The critical time interval for other species may differ. We have also exploited the model presented in this study regarding plague metrics for the conservation of other New Zealand birds such as Nestor meriodionalis (New Zealand kaka) or Mohoua ochrocephala (mohua). The results, however, are not shown here for the sake of brevity. We have defined the plague metrics for the kaka by its breeding season, which is taking place mainly between October and March before years with high seed fall (Wilson et al. 1998; Moorhouse et al. 2003). As the kaka is also mainly vulnerable against stoat predation, the optimal control timing is the same as it is primarily affected by the maximum in the rat density. However, some native species like, for example, the mohua are also under threat from predation by rats. The results for the mohua (not shown here) reveal the optimal control timing is shifted closer to the reproduction event of the stoats in October (i.e., to middle September) due to the main influence of rats in February. Due to indirect effects such as mesopredator release (Soulé et al. 1988), the optimal control derived in this study can in fact be suboptimal regarding other target species (see, e.g., Courchamp et al. (1999) for an example of a similar problem with invasive meso- and invasive superpredator). Hence, before applying the control measure as suggested in this study on a large scale, it should be tested locally, including a monitoring program following the control operation as it is suggested in the review on biological invasions by Courchamp et al. (2003).

One shortcoming of this study is that we developed and parameterized the model using stoat and rat tracking rates. Tracking rates are known to be a saturating activity measure (Gillies and Williams 2013) whereas the percapacity activity tends to decrease with density (Davidson and Morris 2001). Especially stoat trappability does not only change with abundance but also change with factors such as food availability (Alterio et al. 1999). Note that extensive numerical simulations have shown that the strong influence of the control success on the vector population density is robust against parameter variations. Furthermore, we have tested our model against structural sensitivity of functional responses (predation and dispersal) and found no dependence. However, further studies are necessary for better estimates for rat and stoat population densities to obtain more accurate quantitative results.

The results presented here refer to the pest management of stoats threatening the local Apteryx populations. However, pulsed resources lead to irrupting pest populations in many ecosystems worldwide with diverse negative impacts (see the "Introduction" section). The modeling approach presented here is readily applicable to other species in New Zealand or even to completely different case studies to investigate suitable strategies, e.g., seed-rat-mongoose dynamics in Japan (Fukasawa et al. 2013) or seed-rodentraccoon-dog dynamics in Poland (Jedrzejewska and Jedrzejewski 2013). The results for the New Zealand case study indicate the great importance of tailored control strategies in such systems.

Acknowledgments The authors acknowledge valuable discussions with Professor Dave Kelly from the University of Canterbury about the ecological background of this study and the preliminary work of Hannah Kotula with funding from Manaaki Whenua Landcare Research and the University of Canterbury. This work was supported by the Hans Mühlenhoff-Foundation.

Funding Information Open Access funding provided by Projekt DEAL.

Open Access This article is licensed under a Creative Commons Attribution 4.0 International License, which permits use, sharing, adaptation, distribution and reproduction in any medium or format, as long as you give appropriate credit to the original author(s) and the source, provide a link to the Creative Commons licence, and indicate if changes were made. The images or other third party material in this article are included in the article's Creative Commons licence, unless indicated otherwise in a credit line to the material. If material is not included in the article's Creative Commons licence and your intended use is not permitted by statutory regulation or exceeds the permitted use, you will need to obtain permission directly from the copyright holder. To view a copy of this licence, visit http:// creativecommonshorg/licenses/by/4.0/.

\section{Appendix 1. Parameters}

Table 1 shows the variables and parameters used in this study. Note that we sometimes express unit in terms of the state variable for a more straightforward interpretation. If we have taken the parameters from a specific study, the table states the reference. If the parameters are estimated based on the results of particular studies, we have denoted this with based on reference. All submodels have been tested and compared with literature with good agreement of the results.

\section{Appendix 2. Killing proportion}

To compare the control level values $B_{0}$ with data, we define a killing proportion. The expression

$\chi=1-\frac{\min _{t \in \Upsilon} R(t)}{R\left(t=t_{b}\right)}$

defines this proportion. Here, $\min _{t \in \Upsilon} R(t)$ refers to the minimum of the rat population in the 12 months after the bait application $\Upsilon$ over the rat population at bait application time $t_{b}$ in a controlled environment. Controlled environment means that we neglected all other effects on the rat population, e.g., seed fall. We simulated a sample time series of 1000 years calculating $\chi$ for 30 different values 
Table 1 The table shows parameters and variables with values and references used for the numerical simulations of the local model in this study. The units of rat and stoat densities are measured using the index C/100TN (catches per 100 trap nights)

\begin{tabular}{|c|c|c|c|c|}
\hline Symbol & Definition & Value & Unit & Reference \\
\hline$F(t)$ & Resource abundance & - & seeds $\mathrm{m}^{-2}$ & - \\
\hline$R(t)$ & Rat density & - & $\mathrm{C} / 100 \mathrm{TN}$ & - \\
\hline$R_{T}(t)$ & Toxic rat density & - & $\mathrm{C} / 100 \mathrm{TN}$ & - \\
\hline$S_{y}(t)$ & Juvenile stoat density & - & $\mathrm{C} / 100 \mathrm{TN}$ & - \\
\hline$S_{o}(t)$ & Adult stoat density & - & $\mathrm{C} / 100 \mathrm{TN}$ & - \\
\hline$t$ & Time & - & years & - \\
\hline$t_{i}^{* r}$ & Stoat reproduction time & $i+2 / 3$ & years & O'Connor et al. (2006) \\
\hline$\sigma(t)$ & Seed fall & - & seeds $\mathrm{m}^{-2}$ year $^{-1}$ & - \\
\hline$B(t)$ & Bait-induced mortality & - & year $^{-1}$ & - \\
\hline$B_{0}$ & Control level & - & - & - \\
\hline$d$ & Bait decay & 50 & year $^{-1}$ & Holland et al. (2018) \\
\hline$h$ & Resource decay & 9.48 & year $^{-1}$ & Holland et al. (2018) \\
\hline$\rho$ & Density-independent birth (rats) & 3.6 & year $^{-1}$ & Hone et al. (2010) \\
\hline$\mu_{R}$ & Density-dependent mortality (rats) & 18 & rat $^{-1}$ year $^{-1}$ & Based on King and Moller (1997) \\
\hline$\alpha_{1}$ & $\begin{array}{l}\text { Demographic efficiency of rats for } \\
\text { primary resources (seeds) }\end{array}$ & 0.1 & rats seeds ${ }^{-1} \mathrm{~m}^{2}$ & $\begin{array}{l}\text { Based on King and Moller (1997), } \\
\text { Holland et al. (2018) }\end{array}$ \\
\hline$\alpha_{2}$ & $\begin{array}{l}\text { Demographic efficiency of rats for } \\
\text { secondary resources (seed predators) }\end{array}$ & 0.1 & rats seeds ${ }^{-1} \mathrm{~m}^{2}$ & $\begin{array}{l}\text { Based on King and Moller (1997), } \\
\text { Holland et al. (2018) }\end{array}$ \\
\hline$\beta$ & $\begin{array}{l}\text { Bait efficacy regarding } \\
\text { secondary resources }\end{array}$ & 10 & - & Based on Kemp et al. (2018) \\
\hline$c$ & Maximum per capita feeding rate & 67.4 & seeds $\mathrm{m}^{-2}$ rats $^{-1}$ year $^{-1}$ & $\begin{array}{l}\text { Based on King and Moller (1997), } \\
\text { Holland et al. (2018) }\end{array}$ \\
\hline$\epsilon$ & Foraging efficiency of rats & 0.1 & seeds ${ }^{-1} \mathrm{~m}^{2}$ & $\begin{array}{l}\text { Based on King and Moller (1997), } \\
\text { Holland et al. (2018) }\end{array}$ \\
\hline$d_{i}$ & Mortality of toxic rats & 20 & year $^{-1}$ & Based on Meenken and Booth (1997) \\
\hline$\iota$ & Encounter probability of stoats and toxic rats & 1 & $(\text { stoat year })^{-1}$ & Based on Kemp et al. (2018) \\
\hline$\mu_{S 2}$ & Density-dependent mortality of stoats & 0.4 & stoats $^{-1}$ year $^{-1}$ & Based on Kemp et al. (2018) \\
\hline$\kappa$ & Poison-induced mortality & 60 & year $^{-1}$ toxic rats $^{-1}$ & Based on Kemp et al. (2018) \\
\hline$C$ & Seed fall independent resources & 0.69 & seeds $\mathrm{m}^{-2}$ & Median of annual food abundance \\
\hline$\gamma$ & Adjustment factor & 800 & year $^{-1}$ & Based on King et al. (2003) \\
\hline$c_{s}$ & Maximum per capita stoat reproduction & 9 & - & Based on King et al. (2003) \\
\hline$\epsilon_{s}$ & Foraging efficiency of stoats & 0.0018 & seeds ${ }^{-1} \mathrm{~m}^{2}$ & Based on King et al. (2003) \\
\hline$\mu_{S_{y} 1}$ & Density-independent mortality of juvenile stoats & 0.7 & year $^{-1}$ & King et al. (1996) \\
\hline$\mu_{S_{0} 1}$ & Density-independent mortality of adult stoats & 0.5 & year $^{-1}$ & King et al. (1996) \\
\hline$D_{R}$ & Dispersal rate of rats & - & year $^{-1}$ & \\
\hline$D_{S_{o}}$ & Dispersal rate of adult stoats & $100 D_{R}$ & year $^{-1}$ & $\begin{array}{l}\text { Based on Murphy and Dowding (1995), } \\
\text { Clapperton et al. (2006) }\end{array}$ \\
\hline$D_{S_{y}}$ & Maximum dispersal rate of juvenile stoats & $4 D_{S_{o}}$ & year $^{-1}$ & $\begin{array}{l}\text { Based on Murphy and Dowding (1995), } \\
\text { King and McMillan (1982) }\end{array}$ \\
\hline$\psi$ & Territorial competitive exclusion factor & 1 & stoats $^{-1}$ & $\begin{array}{l}\text { Based on Erlinge (1977), } \\
\text { King and McMillan (1982) }\end{array}$ \\
\hline
\end{tabular}




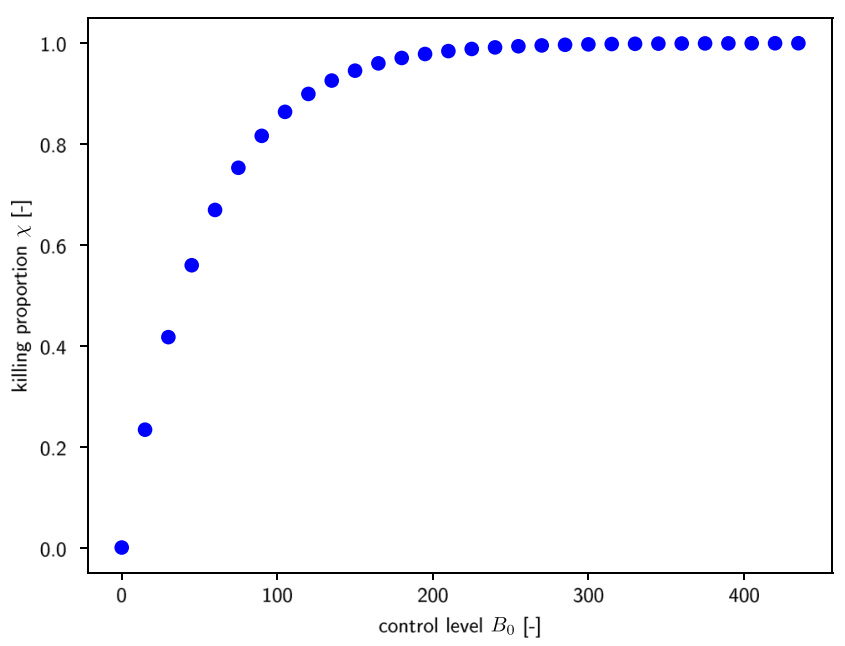

Fig. 6 The killing proportion saturates exponentially with respect to the control level. The figure shows the relationship between control level and killing proportion

of $B_{0}$ and used semi-logarithmic linear regression, to obtain the following relationship for the killing proportion

$\chi=1-e^{\frac{-B_{0}}{49.8}}$

Figure 6 visualizes this relationship.

\section{Appendix 3. Reinvasion time}

A controlled environment without bait application and seed fall and using semi-logarithmic linear regression similar

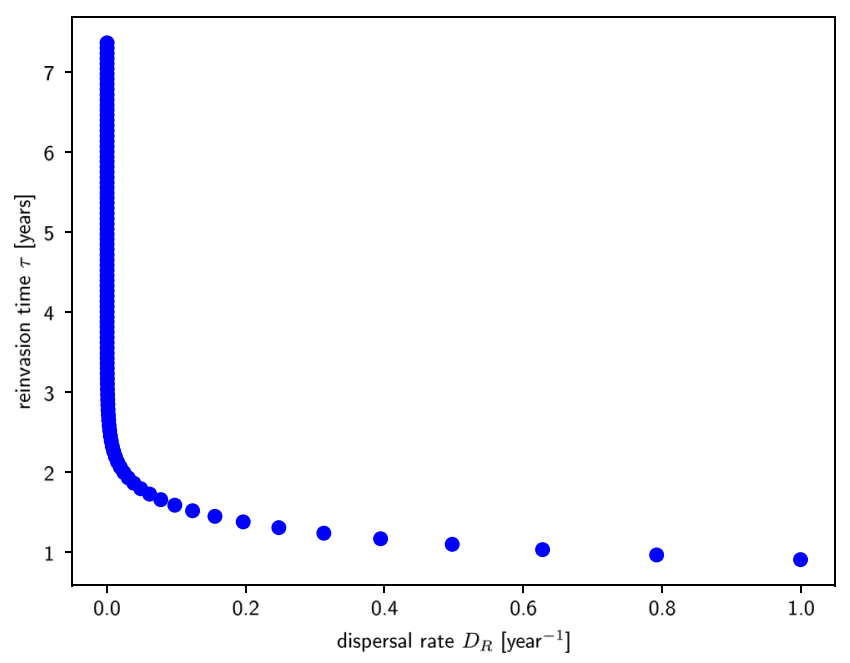

Fig. 7 Reinvasion times decrease exponentially with increasing dispersal rates. The figure shows the relationship between reinvasion time and the dispersal rate of rats to the "Control intensity" section results in the following dependence

$D_{R}=e^{\frac{0.94 \text { years }-\tau}{0.28 y e a r s}}$.

for the time $\tau$ it takes for the rats from invading into a new habitat until the population reaches $90 \%$ of its carrying capacity. Figure 7 visualizes this relationship.

\section{References}

Abramson G, Giuggioli L, Kenkre V, Dragoo J, Parmenter R, Parmenter C, Yates T (2006) Diffusion and home range parameters for rodents: Peromyscus maniculatus in New Mexico. Ecol Complex 3(1):64-70

Allen RB, Mason NW, Richardson SJ, Platt KH (2012) Synchronicity, periodicity and bimodality in inter-annual tree seed production along an elevation gradient. Oikos 121(3):367-376

Alterio N, Moller H, Brown K (1999) Trappability and densities of stoats (Mustela erminea) and ship rats (Rattus rattus) in a south island nothofagus forest, new zealand. N Z J Ecol 23:95100

Bridgman LJ, Innes J, Gillies C, Fitzgerald N, Miller S, King CM (2013) Do ship rats display predatory behaviour towards house mice? Anim Behav 86(2):257-268

Clapperton BK et al (2006) A review of the current knowledge of rodent behaviour in relation to control devices volume 263. Department of Conservation, Science \& Technical Pub.

Cordoleani F, Nerini D, Gauduchon M, Morozov A, Poggiale J-C (2011) Structural sensitivity of biological models revisited. J theor Biol 283(1):82-91

Courchamp F, Chapuis J.-L., Pascal M (2003) Mammal invaders on islands: impact, control and control impact. Biol Rev 78(3):347383

Courchamp F, Langlais M, Sugihara G (1999) Cats protecting birds: modelling the mesopredator release effect. J Animal Ecol 68(2):282-292

Dalgleish HJ, Swihart RK (2012) American chestnut past and future: implications of restoration for resource pulses and consumer populations of eastern U.S. forests. Restor Ecol 20(4):490497

Davidson D, Morris D (2001) Density-dependent foraging effort of deer mice (Peromyscus maniculatus). Funct Ecol 15(5):575583

Dowding JE, Murphy EC (1994) Ecology of ship rats (Rattus rattus) in a kauri (Agathis australis) forest in Northland, New Zealand. New Zealand Journal of Ecology, pp 19-27

Efford M, Fitzgerald B, Karl B, Berben P (2006) Population dynamics of the ship rat Rattus rattus L. in the Orongorongo Valley, New Zealand. New Zealand J Zool 33(4):273-297

Elliot G (2016) The science behind the Department of Conservation's predator control response. Department of Conservation

Elliott G, Kemp J (2016) Large-scale pest control in New Zealand beech forests. Ecol Manag Restor 17(3):200-209

Elliott G, Willans M, Edmonds H, Crouchley D (2010) Stoat invasion, eradication and re-invasion of islands in Fiordland. New Zealand J Zool 37(1):1-12

Erlinge S (1977) Spacing strategy in stoat Mustela erminea. Oikos 28:32-42

Fukasawa K, Miyashita T, Hashimoto T, Tatara M, Abe S (2013) Differential population responses of native and alien rodents to an invasive predator, habitat alteration and plant masting. Proc R Soc B Biol Sci 280(1773):20132075 
Fussmann GF, Blasius B (2005) Community response to enrichment is highly sensitive to model structure. Biol Lett 1(1):9-12

Gillies C, Williams D (2013) DOC tracking tunnel guide: using tracking tunnels to monitor rodents and mustelids. Department of Conservation, Science \& Capability Group, Hamilton, New Zealand, v2.5.2 edition

Green W, Rohan M (2012) Opposition to aerial 1080 poisoning for control of invasive mammals in New Zealand: risk perceptions and agency responses. J R Soc N Z 42(3):185-213

Herrera CM, Jordano P, Guitián J, Traveset A (1998) Annual variability in seed production by woody plants and the masting concept: reassessment of principles and relationship to pollination and seed dispersal. Am Nat 152(4):576-594

Holland EP, Binny RN, James A (2018) Optimal control of irrupting pest populations in a climate-driven ecosystem. PeerJ 6:e6146

Holland EP, James A (2015) Assessing the efficacy of population-level models of mast seeding. Theor Ecol 8(1):121-132

Hone J, Duncan RP, Forsyth DM (2010) Estimates of maximum annual population growth rates $\left(r_{m}\right)$ of mammals and their application in wildlife management. J Appl Ecol 47(3):507-514

Innes J (1990) Ship rat-the handbook of New Zealand mammals. King, CM (ed), pg 206-225

Innes J, Kelly D, Overton JM, Gillies C (2010) Predation and other factors currently limiting New Zealand forest birds. N Z J Ecol 34(1):86

Jedrzejewska B, Jedrzejewski W (2013) Predation in vertebrate communities: the Bialowieza Primeval Forest as a case study, vol 135. Springer Science \& Business Media

Jones C, Pech R, Forrester G, King CM, Murphy EC (2011) Functional responses of an invasive top predator Mustela erminea to invasive meso-predators Rattus rattus and Mus musculus, in New Zealand forests. Wildl Res 38(2):131-140

Kelly D, Geldenhuis A, James A, Penelope Holland E, Plank MJ, Brockie RE, Cowan PE, Harper GA, Lee WG, Maitland MJ et al (2013) Of mast and mean: differential-temperature cue makes mast seeding insensitive to climate change. Ecol Lett 16(1):90-98

Kelly D, Sork VL (2002) Mast seeding in perennial plants: why, how, where? Ann Rev Ecol Syst 33(1):427-447

Kemp JR, Mosen CC, Elliott GP, Hunter CM (2018) Effects of the aerial application of 1080 to control pest mammals on kea reproductive success. N Z J Ecol 42(2):158-168

King C (1983) The relationships between beech (Nothofagus sp.) seedfall and populations of mice (Mus musculus), and the demographic and dietary responses of stoats (Mustela erminea), in three New Zealand forests. J Anim Ecol 52:141-166

King C, Flux M, Innes J, Fitzgerald B (1996) Population biology of small mammals in Pureora Forest Park: 1. Carnivores (Mustela erminea, M. furo, M. nivalis, and Felis catus). New Zealand J Ecol 20:241-251

King C, McMillan C (1982) Population structure and dispersal of peak-year cohorts of stoats (Mustela erminea) in two New Zealand forests, with special reference to control. N Z J Ecol 5:59-66

King C, Moody J (1982) The biology of the stoat (Mustela erminea) in the national parks of New Zealand IV. reproduction. New Zealand J Zool 9(1):103-118

King C (2005) The handbook of New Zealand mammals. Oxford University Press, Oxford

King CM, Innes JG, Gleeson D, Fitzgerald N, Winstanley T, O’Brien B, Bridgman L, Cox N (2011) Reinvasion by ship rats (Rattus rattus) of forest fragments after eradication. Biol Invasions 13(10):2391

King CM, Moller H (1997) Distribution and response of rats Rattus rattus, R. exulans to seedfall in New Zealand beech forests. Pac Conserv Biol 3(2):143-155
King CM, White PC, Purdey DC, Lawrence B (2003) Matching productivity to resource availability in a small predator, the stoat (Mustela erminea). Can J Zool 81(4):662-669

Mcdonald RA, Harris S (2002) Population biology of stoats Mustela erminea and weasels Mustela nivalis on game estates in great britain. J Appl Ecol 39(5):793-805

McQueen S, Lawrence B (2008) Diet of ship rats following a mast event in beech (Nothofagus spp.) forest. N Z J Ecol 32:214-218

Meenken D, Booth L (1997) The risk to dogs of poisoning from sodium monofluoroacetate (1080) residues in possum (Trichosurus vulpecula). N Z J Agric Res 40(4):573-576

Meerburg BG, Singleton GR, Kijlstra A (2009) Rodent-borne diseases and their risks for public health. Crit Rev Microbiol 35(3):221-270

Moorhouse R, Greene T, Dilks P, Powlesland R, Moran L, Taylor G, Jones A, Knegtmans J, Wills D, Pryde M et al (2003) Control of introduced mammalian predators improves kaka Nestor meridionalis breeding success: reversing the decline of a threatened New Zealand parrot. Biol Conserv 110(1):33-44

Morgan D, Thomas M, Meenken D, Nelson P (1997) Less 1080 bait usage in aerial operations to control possums. In: Proceedings of the New Zealand Plant Protection Conference, vol 50, pp 391396

Murphy E, Robbins L, Young J, Dowding J (1999) Secondary poisoning of stoats after an aerial 1080 poison operation in Pureora Forest, New Zealand. N Z J Ecol 23:175-182

Murphy EC, Dowding JE (1995) Ecology of the stoat in Nothofagus forest: home range, habitat use and diet at different stages of the beech mast cycle. N Z J Ecol 19:97-109

Murphy EC, Gillies C, Maddigan F, McMurtrie P, Edge K.-A., Rohan M, Clapperton BK (2016) Flexibility of diet of stoats on Fiordland islands, New Zealand. N Z J Ecol 40(1):114-120

Norbury G (2000) The potential for biological control of stoats (Mustela erminea). New Zealand J Zool 27(3):145-163

O'Connor C, Turner J, Scobie S, Duckworth J (2006) Stoat reproductive biology. Science \& Technical Publishing, Department of Conservation

O’Donnell CF, Dilks PJ, Elliott GP (1996) Control of a stoat (Mustela erminea) population irruption to enhance mohua (yellowhead) (Mohoua ochrocephala) breeding success in New Zealand. New Zealand J Zool 23(3):279-286

Ostfeld RS, Keesing F (2000) Pulsed resources and community dynamics of consumers in terrestrial ecosystems. Trends Ecol Evol 15(6):232-237

Pearse IS, Koenig WD, Knops JM (2014) Cues versus proximate drivers: testing the mechanism behind masting behavior. Oikos 123(2):179-184

Polis GA, Power ME, Huxel GR (2004) Food webs at the landscape level. University of Chicago Press, Chicago

Riney T (1959) Lake Monk expedition: An ecological survey in Southern Fiordland. New Zealand Department of Science and Industry Research Bulletin 135:1-75

Robertson H, Craig E, Gardiner C, Graham P (2016) Short pulse of 1080 improves the survival of brown kiwi chicks in an area subjected to long-term stoat trapping. New Zealand J Zool 43(4):351-362

Ruscoe W, Norbury G, Choquenot D (2006) Trophic interactions among native and introduced animal species. In: Biological invasions in New Zealand, pages 247-263. Springer

Ruscoe WA, Elkinton JS, Choquenot D, Allen RB (2005) Predation of beech seed by mice: effects of numerical and functional responses. J Animal Ecol 74(6):1005-1019

Singleton GR, Belmain S, Brown PR, Aplin K, Htwe NM (2010) Impacts of rodent outbreaks on food security in Asia. Wildl Res 37(5):355-359 
Smith D, Jamieson I, Peach R (2005) Importance of ground weta (Hemiandrus spp.) in stoat (Mustela erminea) diet in small montane valleys and alpine grasslands. N Z J Ecol 29:207214

Soulé M. E., Bolger DT, Alberts AC, Wrights J, Sorice M, Hill S (1988) Reconstructed dynamics of rapid extinctions of chaparralrequiring birds in urban habitat islands. Conserv Biol 2(1):75-92

Warburton B, Cullen R (1995) Cost-effectiveness of different possum control methods

Wardle J et al (1984) The New Zealand beeches: ecology, utilisation and management. New Zealand Forest Service

Wilson P, Karl B, Toft R, Beggs J, Taylor R (1998) The role of introduced predators and competitors in the decline of kaka
(Nestor meridionalis) populations in New Zealand. Biol Conserv 83(2): 175-185

Wiser SK, Hurst JM, Wright EF, Allen RB (2011) New Zealand's forest and shrubland communities: a quantitative classification based on a nationally representative plot network. Appl Veg Sci 14(4):506-523

Wyman TE, Trewick SA, Morgan-Richards M, Noble AD (2011) Mutualism or opportunism? Tree fuchsia (Fuchsia excorticata) and tree weta (Hemideina) interactions. Austral Ecol 36(3):261268

Publisher's note Springer Nature remains neutral with regard to jurisdictional claims in published maps and institutional affiliations. 